\title{
Information Systems in Virtual Corporations: Issues for ERP Based E-business Systems
}

\author{
Samo Bobek, Vojko Potocan, Simona Sternad, and Heri Spicka \\ Faculty of Economics and Business, University of Maribor, Slovenia
}

\author{
samo.bobek@uni-mb.si, vojko.potocan@uni-mb.si, \\ simona.sternad@uni-mb.si, heri.spicka@uni-mb.si.
}

\begin{abstract}
Virtual corporations can be viewed as a network of creative people, resources and ideas connected by inter-organizational information systems and/or by on-line services. Information systems makes virtual corporations more successful, because the communication and collaboration among dispersed business partners are key to making it happen. Virtual corporations can use different information systems on different technological platforms. In the paper we will discuss the possibilities for informational support of the $\mathrm{Cu}$ pertino between partners within virtual corporations with focus on enterprise resource planning solutions, which became more and more important.
\end{abstract}

Keywords: virtual corporations, business networking, e-business, enterprise resource planning, workflow systems, computer supported co-operative work

\section{Introduction}

One of the most interesting organization structures in information age is the virtual corporation (virtual organization). A virtual corporation is an organization composed of several business partners, which through electronic cooperation share costs and resources for the purpose of producing a product or service and increase revenues. Permanent virtual organizations are designed to create or assemble productive resources rapidly, frequently, or to create or assemble a broad range of productive resources (Goldman et.al., 1995). The creation, operation, and management of virtual organizations are heavily dependent on information systems.

The major goals that virtual organizations pursue are:

- Excellence: Each partner brings its core competence.

- Utilization: Resources of partners are utilized more profitably.

- Opportunism: Market opportunity can be met better together than by each individual company.

In most cases partners cooperate within the supply chain of an organization. However, virtual organizations are not necessarily organized along the supply chain. For example, a business partnership may in-

Material published as part of these proceedings, either on-line or in print, is copyrighted by Informing Science. Permission to make digital or paper copy of part or all of these works for personal or classroom use is granted without fee provided that the copies are not made or distributed for profit or commercial advantage AND that copies 1) bear this notice in full and 2) give the full citation on the first page. It is permissible to abstract these works so long as credit is given. To copy in all other cases or to republish or to post on a server or to redistribute to lists requires specific permission from the publisher at Publisher@intormingscience.org clude several partners, each creating a portion of product or service in an area in which they have special advantage; such as expertise or low costs. Therefore virtual organizations can be viewed as a network of creative people, resources and ideas connected by interorganizational information systems and/or by on-line services. 
Information systems make virtual organizations more successful, because the communication and collaboration among dispersed business partners is key to making it happen (Turban et.al, 2000). Business partners can use different information systems on different technological platforms. In the paper we will discuss the possibilities for informational support of the cooperation between partners within virtual networks with focus on enterprise resource planning solutions, which became more and more important.

\section{Virtual Organizations}

In business a new paradigm, in which knowledge and service based systems are revolutionizing organizations, is emerging. Quin (1992) described such organizations as intelligent enterprises. In his study of how knowledge based services and technology are revolutionizing the economy and every corporate strategy, Quin argues that the successful companies - whether in manufacturing or services - will derive their competitive edge not from ephemerally superior products but from a deep understanding of a few highly developed knowledge and service based »core competencies «.

The term »virtual organization « is also often known by other names - »virtual corporation « (Davidow and Malone, 1992), »virtual enterprise « (Cheng, 1996) or »virtual company «(Fischer, 1993), though they all refer to the same concept, there is no consensus on the definition of »virtual organization«. Five main attributes of a virtual organization identified from the cited literature are (Grimshaw and Kwok, 1998):

- alliance for a common goal,

- underlying information and communication technologies,

- vertical integration,

- globalization,

- collaboration.

In manufacturing, as automated manufacture has become more universal, the most significant contribution of value-added in a product have migrated away from manufacturing activities that simply convert raw materials into product toward those knowledge-based service activities that provide the styling features, perceived quality, subjective taste, or marketing presentation values at many different points in the value chain. At each stage, technology has increased the relative power of services. On-line databases and highpowered experimental equipment have revolutionized the research process; CAD/CAE/CAM techniques dominate the design-to-development cycle; »quick response « ordering systems shorten order-to-delivery times; automatic sensing and data entry devices enable »real time« control over quality and inventories; carefully designed expert systems can plan and control the details of new product launches; direct feedback loops from customers on their EPOS systems provide sophisticated market research capabilities; and automated repair systems lower post-sale warranty and service costs. Information technology also allows that the majority of value chain activities can be outsourced or operated by partners. In service companies trends are similar.

A virtual organization has many locations and the need to communicate between those locations, to share information and work collaboratively on that shared information to produce joint products and services, with the use of information systems as facilitators. From this point of view the key features of the virtual organization can therefore be described in the following way:

- a virtual organization is an opportunity-pulled and opportunity-defined integration of core competencies of different partners which is based on information systems

- in a virtual organization a single project can run across different partners on the basis of computer support 
- in a virtual organization experts can be accesses through the computer network

- in a virtual organization participants interact with each other as team members within computer supported collaborative work

- in a virtual organization, companies must be connected electronically so that people within an organization can inter-operate and intra-operate across the electronic business environment, using common tools to navigate around the electronic business environment and share information.

\section{Information Systems for Virtual Organizations}

The information technology supporting the virtual organization model is varied, ranging from simple communication technology such as e-mail, fax and teleconferencing to groupware, videoconferencing and inter-organizational linkages such as EDI (Palmer 1998). All services mentioned are Internet services. Where and when a virtual organization applies distinct information technology and information system it depends on the content and on the characteristics of co-operation.

The business process of a virtual organization is organized according to models as a basis for workflow between partners. It is problematic to construct a comprehensive and sustainable model for all cooperation processes. The problem is to some extent a question of stable structures in co-operation processes. The most structured and frequently recurring processes are called pre-determined processes. Unique and flexible processes, which are unstructured, are called ad-hoc processes. Processes in between these extremes are referred to as semi-structured processes. Each process type within virtual organization requires different information system.

Unstructured and semi structured processes offer limited possibilities for workflow automation. Less structured co-operation processes can be supported by supplying employees with a set of diverse communication media, each consisting of certain functionalities. The most suitable for this type of processes are information systems, which are based on technologies for computer supported co-operative work

(CSCW). Approaching this question a virtual organization has first to develop a layer framework, which provides a description of the relationship between co-ordination and co-operation processes, the underlying human communication processes and communication media (Englert et.al, 1996). Than a document based information system can be developed using groupware technology (i.e. Lotus Notes). Such information system should provide a toolbox for the user, which contains a sufficient set of communication media to deal with a specific context.

On the other hand, structured and predetermined processes require workflow automation and interorganizational information systems, which support data exchange between information systems of partners in a virtual organization. A workflow information system controls the responsible person with relevant support and the necessary data at the right point in the process. They also allow organizations to dynamically define, execute, manage, and modify business processes. The workflow information system controls the process flow. It connects the screen forms needed to input and output data on each process step. Workflow information systems are suited for well-structured processes, where clearly defined rules determine the execution order of the process steps.

In the last few years, however, we have seen a growing tendency towards package ware. Systems in areas ranging from sales and marketing, production and procurement are supported by systems called enterprise resource planning (ERP) solutions. These information systems automate generic versions of the business process, often internally using a workflow engine for process customization, control and automation. In recent years we have also seen a growing tendency towards seamless integration of business processes in virtual organizations. Information technology and the Internet play a crucial role here. Global companies use the Intranet or Extranet to communicate internally using Internet technologies. But the integration of business processes does not stop at company boundaries. Supply chain processes are integrated using web 
and other e-commerce technologies from the supplier through the producer to the consumer (Glory, 2000). To link business processes in virtual organizations, the underlying information systems needs the capability to link information seamlessly and automatically.

\section{ERP Solutions in Virtual Organizations}

Enterprise resource planning (ERP) solutions provide support in areas such as accounting and controlling, production and material management, quality management and plant maintenance, sales and marketing, project management, and human resources. Leading vendors for large companies are SAP, Oracle, Ban, etc. SAP is by far the largest ERP vendor (Glory, 2000). With its MySAP.com initiative, it is moving quickly into e-business area, combining SAP standard business applications with standard Internet technologies. ERP and e-business integration defines new information systems architecture of virtual organizations, which can be described as ERP based e-business.

ERP based E-business improves business performance by using information technologies and open standards to connect suppliers, partners and customers at all steps along the value chain. These information systems can significantly improve business performance by strengthening the linkages in the value chain between businesses, and between a business and the ultimate customer. Streamlining business processes in virtual organizations involves two imperatives: trust among business partners and agreement on standard ways of working, and agreement on common data exchange standards that facilitates dialogue on mutual business events over the Internet.

Oesterle, Fleisch and Alt (2000) suggest a model that reflects the major principles of networked enterprise - virtual organization. The four building blocks are:

- networked processes - e-business enabled direct co-operation between partners and organization core processes

- business bus - e-business enabled co-operation between partners based on high level of standardization

- electronic services - e-business enabled co-operation with externalized services

- $\quad$ service integrator - e-business enabled co-operation with new players - »infomediaries « - within business networking.

In order to make rational decisions about how to deploy resources in implementing ERP based e-business, a virtual company must know both its starting position in the e-business panorama and its desired end state, relative to the various possibilities. The ERP/e-business matrix (Noris et.al, 2000) defines five scenarios for ERP based e-business:

- channel enhancement - modifying existing business processes

- value-chain integration - integrating suppliers, partners and customers through e- business customer relationship management (eCRM) and through e-business supply chain management (eSCM)

- industry transformation - restructuring virtual organization

- convergence - partnering with companies from different industries.

ERP based e-business information systems require extended ERP functionality. In the e-world, the focus is no longer just on how well an ERP system can store and manage data and move it around within the company. It is now on both adding value to that data to turn it into information and knowledge, and on moving that data and information across virtual organization to create knowledgeable extended organizations. Some areas in which ERP systems will be expanded are: 
- web based customer relationship management (eCRM) which has to support e-commerce and data mining

- advanced planning and scheduling which has to provide a better way of managing information flow connected with manufacture resource planning

- web based supply chain management (eSCM)

- value based strategic management of virtual organization (i.e virtual organization sell plan, build plan, etc)

- shared services in the way of creating virtual shared service centers (SSC) in virtual organization.

The major benefit of ERP based e-business information systems will be realized when production planning and procurement of all materials - production and nonproduction - will be, together with selling and buying, web-enabled and integrated.

\section{Conclusion}

The business process of a virtual organization is organized according to models as a basis for workflow between partners. The models for cooperation processes differ according to how stable structures in cooperation processes can be establish within a virtual organization. The most structured and frequently recurring processes are called pre-determined processes. Unique and flexible processes which are unstructured are called ad-hoc processes. Processes in between these extremes are referred to as semi-structured processes. Each process type within virtual organization requires different information system.

Unstructured and semistructured processes offer limited possibilities for workflow automation. Less structured cooperation processes can be supported by supplying employees with a set of diverse communication media, each consisting of certain functionalities. The most suitable for this type of processes are information systems which are based on technologies for computer supported cooperative work (CSCW).

Structured and predetermined processes require workflow automation and interorganizational information systems which support data exchange between information systems of partners in virtual organization. A workflow information system provides the responsible person with relevant support and the necessary data at the right point in the process. Systems in areas ranging from sales and marketing, production and procurement are supported by systems called enterprise resource planning (ERP) solutions. These information systems automate generic versions of the business process, often internally using a workflow engine for process customization, control and automation.

ERP and e-business integration defines the new information systems architecture of virtual organizations which can be described as ERP based e-business. ERP based e-business information systems require extended ERP functionality. In the e-world, the focus is no longer just on how well an ERP system can store and manage data and move it around within the company. It is now on both adding value to that data to turn it into information and knowledge, and on moving that data and information across virtual organization to create knowledgeable extended organizations.

\section{References}

Cheng W., (1996). The virtual enterprise: Beyond time, place and form. Economic Bulletin. Singapore International Chamber of Commerce, 5-7, February.

Davidow W.H., Malone M., (1995). The virtual corporation. Harper Business.

Englert J., et.al., (1996). Beyond Automation: A framework for supporting cooperation, in: Coelho D.J. et.al (ed.): Proceedings of $4^{\text {th }}$ European Conference on Information Systems, Lisbon Portugal, pp. 91-104. 
Information Systems in Virtual Corporations

Fischer A., (1993). A global concept - Virtual companies. The Financial Times. pp.12., 16 July.

Gloor P., (2000). Making the E-business Transformation. Springer Verlag.

Goldman et.al., (1995). Competitors and Virtual organizations. Van Nostrand Reinhold.

Grimshaw D.J. and Kwok F.T.S., (1998). The business benefits of the virtual organization. in: Igbaria M, and Tan M. (ed.) The virtual workplace. Idea group publishing. pp.45-71.

Noris G., et.al, (2000). E-business and ERP: Transforming the Enterprise. Wiley.

Oesterle H., Fleisch E., Alt R., (2000). Business Networking: Shaping Enterprise Relationships on the Internet. Springer Verlag.

Palmer J.W., (1998). The use of information technology in virtual organization. in: Igbaria M, and Tan M. (ed.) The virtual workplace. Idea group publishing, pp.71-86.

Quin J.B., (1992). Intelligent Enterprise. Free Press.

Turban E., et.al, (2000). Electronic Commerce: A managerial perspective. Prentice Hall. 